Research Article

\title{
Importance-Performance Analysis of Prefabricated Building Sustainability: A Case Study of Guangzhou
}

\author{
Linlin Xie $\mathbb{D D}^{1}{ }^{1}$ Yajiao Chen $\mathbb{D}^{1},{ }^{1}$ Bo Xia $\mathbb{D D}^{2},{ }^{2}$ and Chunxiang Hua $\mathbb{D D}^{3}$ \\ ${ }^{1}$ School of Civil Engineering and Transportation, South China University of Technology, Guangzhou 510641, China \\ ${ }^{2}$ School of Civil Engineering and Built Environment, Queensland University of Technology, Brisbane 4001, Australia \\ ${ }^{3}$ School of Economics and Management, Tongji University, Shanghai 200092, China
}

Correspondence should be addressed to Yajiao Chen; 942034120@qq.com

Received 24 May 2020; Revised 29 June 2020; Accepted 24 July 2020; Published 17 August 2020

Academic Editor: Tayfun Dede

Copyright ( $\odot 2020$ Linlin Xie et al. This is an open access article distributed under the Creative Commons Attribution License, which permits unrestricted use, distribution, and reproduction in any medium, provided the original work is properly cited.

In the era of sustainability as the development concept, prefabricated buildings have gradually become an important way to achieve sustainable development of the construction process due to the advantages of high construction speed, energy-saving, and environmental protection. In order to make the prefabricated building develop in a sustainable direction, it is necessary to understand the importance and performance of the critical sustainability aspects of the prefabricated building. However, the existing research has not fully explored this point, and classification research on all aspects of sustainability according to the management priorities of sustainable development is lacking. The present study determines the critical sustainability characterization items (criteria) of prefabricated buildings and uses the importance-performance analysis (IPA) method to explore the sustainability importance and performance level of prefabricated buildings in Guangzhou on the basis of the three dimensions of economic, social, and ecological sustainability. In particular, this study revises the traditional IPA method and uses the comprehensive weight obtained by the analytical network process- (ANP-) entropy weight method to obtain the importance of items. Results show that items "environmental protection" and "construction civilization" are of high importance and perform well. "Construction cost" and "product quality" are considered high-importance items with relatively poor performance; that is, these areas require urgent improvement actions. The "policy support" item at the intersection of IPA coordinates is also an aspect worthy of attention and discussion. This study provides a useful reference for decision-makers and relevant personnel on determining the priority of project management and achieving the optimal allocation of resources to promote the sustainable development of prefabricated buildings.

\section{Introduction}

The construction industry significantly impacts the economy, society, and ecology globally $[1,2]$. The industry is also always accompanied by a high proportion of energy consumption [3], which significantly impacts sustainable development. The report of Intergovernmental Panel on Climate Change indicated that buildings account for approximately $40 \%$ of global energy consumption [4]. Approximately $40 \%$ of energy consumption and $36 \%$ of carbon dioxide emissions in the EU come from buildings [5]. Over the past decade, construction activity in China has increased significantly, especially in terms of construction area; the resulting construction and demolition waste has reached approximately 1.55 to 2.4 billion tons in China [6]. Therefore, shifting from traditional construction methods to sustainable ones is necessary [7]. In particular, the increase in people's awareness of environmental pollution and the accompanying social problems has facilitated the acceptance of the idea of sustainable construction by the construction industry $[8,9]$.

In response to the development of sustainable construction, the construction industry has paid increasing attention to the use of modular prefabrication in recent years. Prefabrication can overcome the shortcomings of traditional construction methods and is considered an effective method to reduce construction waste from the source $[10,11]$. Prefabrication refers to assembling structural 
components at a factory or other manufacturing sites and transporting complete components or subcomponents to the construction site where the structure is located [12]. Compared with the traditional cast-in-place construction, the prefabricated building is a large-scale production method. It transfers part of the traditional site construction work to the factory for completion [13] and brings various advantages, such as shortening construction time, improving quality, saving resources, and reducing environmental pollution [14-18]. Prefabricated buildings have been widely accepted as an alternative to traditional cast-in-place structures because of their advantages [19]. As a result, prefabricated buildings become an inevitable trend in the future development of the construction industry.

In past research, the sustainability of prefabricated buildings has been studied in different aspects. Some scholars have investigated the sustainability performance evaluation of prefabricated buildings $[20,21]$. In addition, many studies have shown the results of analysis of affecting factors of the sustainable development of prefabricated buildings [22, 23]. However, these studies mainly focus on the environmental sustainability of prefabricated buildings, while the economic and social sustainability studies are relatively lacking. The triple bottom line (TBL) sustainability standards in all dimensions should be fully considered in the sustainable development of the entire prefabricated building [24]. Moreover, few studies have comprehensively considered the importance and performance of the sustainability of prefabricated buildings. Attitude and awareness are the prerequisites for sustainable development actions $[25,26]$. If we do not pay attention to certain sustainability aspects of prefabricated buildings, then this aspect may not perform well. Therefore, in the research of the sustainability of prefabricated buildings, the following questions need to be paid attention to: what aspects are attached with importance to the sustainability of prefabricated buildings? What is the current performance of prefabricated building construction in all aspects of sustainability? However, the existing research rarely reviews the importance views and performance levels of critical sustainability aspects (including economic, social, and environmental aspects) of prefabricated buildings, and the interdependence among criteria is ignored. These studies cannot determine the critical sustainability aspects that require management actions (such as the aspects of high importance but the worst performance). It lacks proper classification according to management priorities and cannot determine effective ways to promote the sustainable development of prefabricated buildings.

To fill these gaps in research, this study identifies critical items that can characterize the sustainability importance and performance level of prefabricated buildings from the perspective of TBL categories, namely, the economic, social, and ecological dimensions. To review the importance and performance level of various sustainability aspects of prefabricated buildings, this study introduces the importance-performance analysis (IPA) method into the field of construction engineering, explores the relationship between the importance and performance of prefabricated buildings in sustainability characterization items, and finds the key development ways. IPA is a useful tool to identify the most critical items related to management behavioral requirements. The criteria involved in the sustainability assessment of prefabricated buildings are usually complex and have different interrelations given that it is a complex decisionmaking issue [27]. Therefore, considering the interdependence of criteria in the weighting process is important [28]. Analytical network process (ANP) is a useful method to deal with the interdependency among criteria in complex systems [29]. On this basis, this study attempts to modify IPA technology by taking the comprehensive weight of ANP and entropy weight method as the measurement of the importance of each item to improve the shortcomings of traditional IPA method in the measurement of the importance of the item in IPA technology.

High quality, high efficiency, and sustainable development are receiving unprecedented attention [30], and the production mode involving the installation of prefabricated components is still new for developing countries, such as China [31]. Therefore, the sustainable research of prefabricated building is important in the development stage of sustainable building. This study explores the importance and performance level of each key sustainability aspect of prefabricated buildings in Guangzhou based on the revised IPA method. This study aims to reveal the importance and performance of various criteria for the sustainability of prefabricated buildings and determine the most important and least important aspects and the performance levels shown in these aspects. This paper proposes targeted development strategies by categorizing these criteria according to management priorities. It can provide theoretical basis and practical guidance for promoting the effective allocation of resources and improving the sustainable development of prefabricated buildings. In addition, the application of IPA technology in this study can also provide a feasible method and idea for future IPA research in the field of construction. The revised IPA technology in this study considers the mutual influence among criteria and sets a reasonable confidence interval, which can be used as an effective tool for identifying key criteria related to management actions.

\section{Literature Review}

Prefabricated buildings, which are an important part of construction industrialization, are receiving an increasing attention [32, 33]. Previous research has used various terms related to prefabricated buildings, including "prefabricated" [34], "prefabricated concrete building" [35], "industrialized building" [36, 37], and "off-site building" [38]. Some research results have shown that the use of the concept of product modularity is beneficial to traditional construction [39]. The emergence of prefabricated buildings helps solve the problems of large energy consumption and serious environmental pollution in traditional cast-in-place buildings [40]. Through the use of standardized design, factory prefabrication, and prefabricated production methods, the building is decomposed and converted from on-site construction to on-site assembly; this way not only can greatly save the construction period but also have outstanding 
performance in improving labor productivity, saving energy, and protecting the environment [41]. Therefore, prefabricated building is considered the future of the construction industry [42] and is widely used in many countries as an effective way to help the construction industry pursue sustainable development $[43,44]$.

In past research, many studies have proven that fabricated technology can help improve the sustainable performance of all aspects of the building, including economic, social, and ecological advantages. For example, Boyd et al. [45] enumerated the advantages of off-site construction in terms of construction time, building quality, and occupational health and safety. Tam et al. [46] identified the advantages of using prefabrication in improving the quality of prefabricated products, reducing construction time and costs, and enhancing environmental performance and aesthetics. Cao et al. [47] proven that prefabrication has obvious advantages in terms of material consumption, energy use, and drainage. Wang et al. [48] evaluated the environmental impact of prefabricated and traditional cast-in-place buildings in the building life cycle by using a building with a $40 \%$ assembly rate in Japan as a case study. The results showed that the total energy consumption and carbon emissions of prefabricated buildings are $7.54 \%$ and $7.17 \%$ lower than those of traditional cast-in-place buildings during the entire life cycle. On the issue of building sustainability, the implementation performance evaluation of relevant criteria is an important research content.

After years of research and exploration, many different methods have been developed to quantify and evaluate the sustainability of buildings. Sustainability assessment systems have been used in the construction industry for many years. Sustainability involves three critical dimensions, namely, the environment, economy, and society, also known as the TBL [49]. The built environment and related processes significantly influence the TBL dimension of sustainable development [50]. Sustainability assessments aim to collect and provide information to simplify the decision-making process [51]. The development of assessment methods and corresponding tools is a challenge in academia and practice. An important category of sustainability assessment methods is the sustainable building rating system. Studies have shown that more than 600 sustainability assessment rating systems are currently available worldwide [52]. For example, the LEED developed by the American Green Building Association, BREEAM developed by the British Building Research Center, GBC initiated and led by the Canadian Ministry of Natural Resources, CASBEE of the Japanese Ministry of Environmental Protection, German Ecological Building Guide LNB, and NABERS of Australian Architecture Environmental assessment systems are relatively common assessment systems. Different evaluation systems will vary with different national backgrounds and cultures. Understanding the relationship and importance of the criteria used in these assessment systems is necessary to help practitioners and governments implement measures to encourage sustainable construction [29]. However, the number of studies to explore the relevance and weight of these evaluation criteria is limited. These sustainability rating systems also expose many shortcomings during use process, such as the complexity and diversity of standards, the bureaucratic evaluation process, and the high use cost [53]. In addition, these assessment tools rarely comprehensively consider multiple aspects of sustainability and generally pay insufficient attention to the economic and social aspects of sustainability [54].

In addition to the abovementioned sustainability assessment systems developed by organizations or institutions, many researchers have adopted various methods to evaluate the sustainable performance of buildings by using principal component analysis, analytic hierarchy process, and other decision-making methods to establish models $[54,55]$. In recent years, people's understanding of sustainable development of buildings has changed. Initially, emphasis was placed on resource constraints, that is, energy consumption and ways to reduce the impact on the natural environment [56]. Over the past 10 years, research has focused on building and construction technology issues, such as materials, structural components, building technology, and energy power. For example, Braganca et al. [51] proposed the viewpoint of sustainability assessment for the whole building from the current situation of building sustainability assessment, the feasibility study of performance analysis, and the development of building life cycle extension assessment. They also introduced and discussed the first step of the sustainability assessment method for Portuguese residential buildings. Tsai et al. [57] proposed an evaluation model for selecting green building projects by defining a series of environmental sustainability standards (such as energy efficiency and resource conservation). Wongbumru and Dewancker [58] used a questionnaire for postevaluation, and the information provided by the research results will help improve the sustainability of new building development. Atanda and Öztürk [59] analyzed the frequency data and research results to identify some potential factors that will influence construction practitioners to make the correct decision for selecting and implementing social standards in green building assessment tools. It should be mentioned that sustainable architecture is considered to achieve balanced development in all aspects of the environment, economy, and society [60]. However, many works only focus on environmental issues or only use one or very limited standards to evaluate the sustainable performance of buildings. Most of them focus on the ecological environment, especially on the energy-saving performance of buildings but pay little attention to the economic and social aspects of sustainability. This situation has led to a single dimension of the study and the lack of comprehensive consideration of multidimensional sustainability aspects.

Related research on the sustainability of prefabricated buildings can be classified into two aspects: one is the sustainability performance evaluation of prefabricated buildings. As with ordinary buildings, many studies have focused on one or a very limited number of criteria to discuss the sustainable benefits of prefabricated buildings. For example, Yong-Woo et al. [61] applied lean and agile ideas to prefabricated building supply chain systems to assess their environmental benefits. Dong et al. [62] compared the 
carbon emissions of precast and cast-in-situ buildings during the construction phase based on the life cycle assessment method and took a residential project in Hong Kong as a case. The results confirmed that the prefabricated construction method can achieve the emission reduction compared with cast-in-place construction method. Mohammad and Kasun [63] studied the environmental performance of prefabricated buildings over their life cycle. They also provided a comprehensive review of the advantages and challenges of prefabricated building construction methods compared with traditional methods. Liu et al. [64] used a process-based approach to assess carbon emissions during the off-site factory prefabrication manufacturing process and designed a carbon emission benchmark for the energy assessment of prefabricated buildings in China. On the other hand, most research topics are about the analysis of the influencing factors of the sustainable development of prefabricated buildings. Many scholars have explored the influencing factors of the sustainable development of fabricated buildings for its promotion. For example, Li et al. [65] analyzed the constraints on sustainable development of prefabricated buildings from the four aspects of market, economy, policy, and technology. The model revealed the relationship among the factors and identified the key influencing factors. Riduan and Jay [66] explored the improvement of the ecological performance of industrialized building systems and analyzed the potential key sustainable drivers and constraints of prefabricated building applications using the SWOT method. Chang et al. [23] analyzed the advantages and disadvantages of prefabricated buildings from the perspective of environmental sustainability and resources, identifying the obstacles to the development of prefabricated buildings. The current research status reveals that many existing studies focus only on unilateral research on the economic, social, and natural sustainability of prefabricated buildings, especially on environmental sustainability. However, sustainability is a complicated combination covering economic, social, and environmental dimensions, which makes the problem more complex [67]. The sustainability aspects of prefabricated buildings should cover the three dimensions of economy, society, and environment to promote their sustainable transformation. Moreover, for the sustainable development of prefabricated buildings, focusing on the most important but relatively poor performance is also necessary to prioritize the allocation of limited resources to the worst performing but important aspects of sustainability.

The construction industry significantly impacts the economy, society, and the environment [68]. Understanding and evaluating the importance and performance of prefabricated buildings in terms of sustainability are important to sustainably develop these buildings, but the existing studies have not adequately discussed this issue. On the other hand, the most important step in assessing building sustainability is to develop appropriate sustainability assessment standards [63]. All applicable TBL sustainability standards should be fully addressed throughout the life cycle. Many previous studies do not analyze the sustainable performance level of prefabricated buildings and only focus on the study of a single dimension. Therefore, the developed methods are insufficient in the analysis of developing prefabricated buildings with low sustainability to high sustainability. Moreover, the research results focusing on the importance or performance of sustainability indicate that few works comprehensively and simultaneously study the importance and performance evaluation of sustainability in prefabricated buildings. In China, the government has adopted strict measures to promote the development of prefabricated buildings. The policy requires that at least $30 \%$ of new buildings must adopt prefabricated construction methods by 2026 [69]. However, the proportion of prefabricated buildings in China's existing building stock is still relatively low, and the buildings are at the initial stage of development [29]. The existing research is insufficient to identify critical sustainability aspects of the development of prefabricated buildings and does not properly categorize various aspects according to management priorities and identify effective ways to promote development. In addition, items with different levels of sustainability performance need to adopt differentiated implementation methods for balancing the sustainable development of prefabricated buildings. Therefore, this study comprehensively considers the sustainability of the three dimensions of ecology, economy, and society and regards the interdependence among the evaluation criteria using the revised IPA tools to analyze the importance and performance of the evaluation items for overcoming the shortcomings of the abovementioned research.

\section{Research Methodology}

3.1. Research Framework. In China's prefabricated building development, only prefabricated building demonstration cities, such as Shenyang, Beijing, Shanghai, and Shenzhen, have a certain scale of industrial chain and base at present. Compared with the few demonstration cities, most cities in China, including Guangzhou, although the development of prefabricated buildings has been gradually carried out, the overall development trend is still relatively slow. This study takes Guangzhou as the representative of most domestic cities and uses the IPA method to study the sustainable development of prefabricated buildings. The research first screens and determines the critical sustainability characterization items of prefabricated buildings through literature analysis and expert interviews. Then, IPA is used to analyze the correlation between importance and performance of prefabricated buildings in Guangzhou. This study uses the combined weights of ANP method and entropy weight method to measure the importance of items. Finally, some targeted construction opinions on the direction and countermeasures of promoting the sustainable development of prefabricated buildings are proposed on the basis of the results of IPA. Figure 1 illustrates the framework and methodology of this study.

\subsection{Research Method}

3.2.1. Importance-Performance Analysis. The IPA technology was originally proposed by Martilla and James [70]; and it is a useful tool for identifying the most critical corporate 


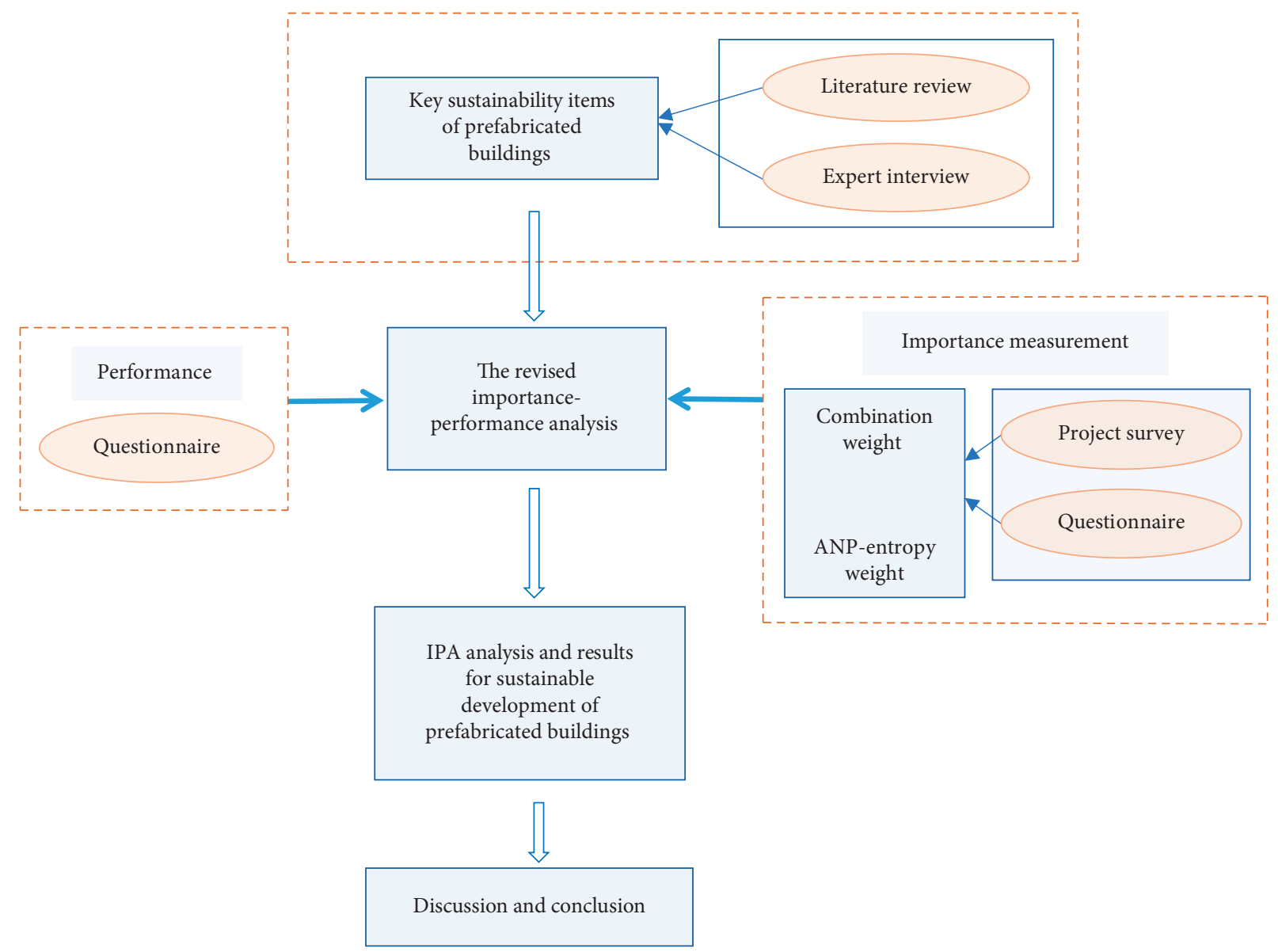

FIGURE 1: Research framework.

management behavior needs. It can help decision-makers determine management priorities [71, 72], help prioritize improvements, and mobilize and deploy scarce resources where they are most needed [73]. IPA technology is currently a popular management tool and has been greatly welcomed in many fields, such as food, education, banking, healthcare, e-commerce, public administration, and tourism [74-77]. IPA is easy to apply in various situations and can make strategic recommendations [78]. In the field of architecture, a few scholars have used IPA to study the transition of construction companies to sustainable development [67], sustainable attitudes and performance of construction companies and their employees [68], and China's prefabricated construction risks [79]. Overall, the IPA method has very limited application in the field of construction engineering and has not been effectively used yet. Determining the sustainability aspects that are considered to be the most important, least important, worst performing, and best performing is necessary for the development of prefabricated buildings to promote their sustainability. This study attempts to apply the IPA method to the sustainability research of prefabricated buildings, pay attention to the importance and performance of various items, and seek a more suitable research method for the sustainable development of prefabricated buildings.
In IPA, two-dimensional coordinates are drawn to reflect their relative relationship [80]. The $x$-axis represents the performance of items, and the $y$-axis represents the importance of items. Thus, the chart is divided into four quadrants.

Quadrant I (Keep Up the Good Work): Importance and performance are high. If the evaluation item locates in this quadrant, it indicates that the item plays an important role in the sustainable performance of prefabricated buildings, with a high contribution value, and is currently developing well. The follow-up development idea is to maintain or promote innovation on the basis of the original.

Quadrant II (Concentrate Here): Low performance but high importance. If the evaluation item locates in this quadrant, it indicates that the item plays a significant role in the sustainable performance of prefabricated buildings and has a high contribution value. However, its current status has not reached the performance development expectations. Therefore, the items in this quadrant need urgent attention, and focusing on improvement actions in this region will have the greatest impact.

Quadrant III (Low Priority): Low performance and importance. If the evaluation item locates in this 
quadrant, it indicates that the item plays a small role in the sustainable performance of prefabricated buildings, with a low contribution value, and is currently underdeveloped. The items in this quadrant are considered to be relatively less important areas and are not a priority for implementing improvement measures.

Quadrant IV (Possible Overkill): High performance but low importance. If the evaluation item locates in this quadrant, it indicates that the item plays a less important role in the sustainable performance of prefabricated buildings and has a low contribution value. However, the item is currently developing well. Therefore, improper resource allocation or investing in these items may cause excessive waste.

Although IPA has been used in the research for a long time, its application has some problems. In this study, IPA is modified according to the following three problems: (1) the location of the two-dimensional coordinate center of IPA, (2) the measurement of the importance of the items, and (3) the region division of quadrant edge items. The revised IPA coordinates are shown in Figure 2.

The first question involves the determination of the position of the IPA coordinate center. Determining the optimal position of the coordinate center is a major problem in applying the IPA method [81]. The placement of most IPA center points is divided into two methods: the "scale-centric" and "data-centric" methods. However, past IPA surveys indicate that many respondents tend to overstate the importance and performance scores, which is known as a "cap effect" [82]. As a result, "scale-centric" IPA mapping may not reveal some of the differences between respondents' assessments of importance and performance. To minimize this upper-limit effect, a "data-centric" IPA mapping method is used in this study. The median, which is a measure of central tendency, is theoretically preferable to the average considering that true interval scales may not exist [70]. On the basis of the characteristics of the data obtained in this study, the median intersection of the metrics of importance and performance is taken as the origin of the IPA coordinates. Among them, the measure of importance takes the item weight value calculated on the basis of the ANP-entropy weight method, and the measure of performance takes the average value of each sample measurement.

The second question involves the measurement of the importance of items. A measure of the importance of items is meaningful for prioritizing resource allocation [83]. The use of absolute importance rather than relative importance greatly limits the predictive power of the importance measure [84]. Some studies have used more sophisticated methods to directly measure importance, including pairwise comparison methods (such as analytic hierarchy processes). Mouthino et al. [85] considered this method to be broad, flexible, and suitable for deriving numerical measures of the relative importance of decision variables. The treatment of the importance of items in the current study abandons the traditional method of directly measuring with a 5-level Likert scale to more scientifically measure the importance of

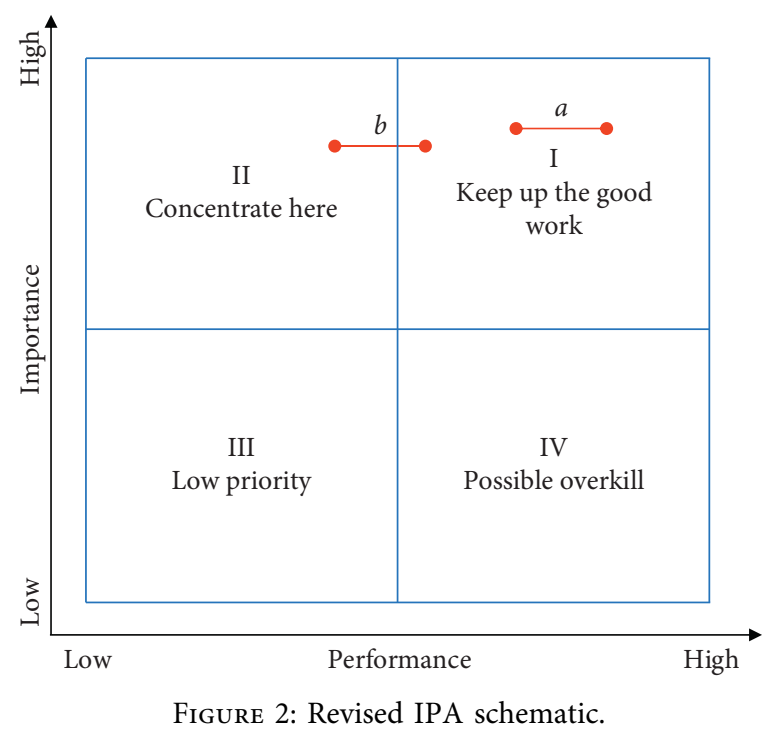

each item of the sustainability of prefabricated buildings. The ANP-entropy weight method, which can reflect the interaction among criteria, is used as a way to measure the importance of each item for improving the performance of the items in a more profound and targeted manner.

The third issue involves the regional division of marginal items. Data representing the performance of the items identify certain areas for improvement and the effectiveness of the organization [83]. Some items may firmly belong to the "Keep Up the Good Work" quadrant; other items may belong to the "Concentrate Here" quadrant but are very close to the "Keep Up the Good Work" quadrant boundary. Traditional IPA cannot distinguish between items assigned to the same quadrant; thus, decision-makers may fail to provide correct management decisions for boundary items [86]. The Tarrant-Smith [87] framework is used in this study to make IPA more sensitive to corresponding changes for addressing the aforementioned issue. For each item, the standard error (SE) of the items' performance value is calculated and then added to the data points on the IPA chart. A horizontally extended confidence interval (CI) is established on the basis of the value of SE, centering on the average value, and the CI is calculated as shown in (1). For item $a$ in Figure 2, the CI for the average performance is within the first quadrant, which indicates that the average value of this item in the figure is a true reflection of the respondents' attitudes. In the case of item $b$, the CI value of the item spans the area of two quadrants. At this time, decision-makers cannot guarantee that the item will be accurately assigned to a single quadrant:

$$
\mathrm{CI}_{P}^{i}=\frac{u\left(P^{i}\right) \pm S\left(P^{i}\right)}{\sqrt{n}},
$$

where $\mathrm{CI}_{P}^{i}$ represents the CI of performance of item $i, u\left(P^{i}\right)$ is the average performance of item $i, S\left(P^{i}\right)$ represents the standard deviation of performance of item $i$, and $n$ is the sample number. 
3.2.2. ANP-Entropy Weight Method. The methods for determining the weight of items can be roughly divided into two types: subjective and objective assignment methods [88]. The weight assignment in the subjective weighting method mainly depends on the decision-maker's experience and decision opinions with strong subjectivity and weak objectivity. Although the objective weighting method is based on mathematics, the weight obtained from the actual data of the evaluation matrix may be contrary to the actual importance of the index [89]. This study adopts the combination of ANP and entropy weight method to measure the importance of the item for avoiding too subjective or objective evaluation results and fully considering the interaction among evaluation criteria. This way ensures the minimum impact of the item weight on the evaluation results.

ANP is a subjective weighting method that can calculate the subjective weight of each item. The ANP model can measure all possible interrelationships among criteria while the analytic hierarchy process or rating law cannot [90]. In the case where the research object needs to consider and quantify the correlation among some criteria, ANP provides a more realistic method and better analysis for decisionmaking problems. This advantage is extremely important [91, 92]. The application of ANP mainly includes three main steps: establishing hierarchy model, constructing judgment matrix, and forming supermatrix and final priority [93].

The entropy method is a weighting method with strong objectivity [94]. This study uses the entropy weight method to determine the objective weight of items. Information entropy describes the degree of dispersion of some item data. A great dispersion corresponds to a great impact of the item on the evaluation results and a greater weight of the item [95]. The calculation principle of the entropy weight method is mainly to calculate the entropy weight by obtaining the entropy value [96].

The weight combination formula obtained by modifying the ANP method using the entropy weight method is as follows [97]:

$$
W=\alpha W_{i}^{a}+(1-\alpha) W_{i}^{e},
$$

where $W$ is the combined weight determined by the ANPentropy weight method, $W_{i}^{a}$ is the weight calculated using the ANP, and $W_{i}^{e}$ is the weight calculated using the entropy weight method.

To achieve the minimum sum of squared deviations of $W_{i}^{a}, W_{i}^{e}$, and $W$, the function is established as follows:

$$
\min W=\sum_{i=1}^{n}\left[\left(W_{i}-W_{i}^{a}\right)^{2}+\left(W_{i}-W_{i}^{e}\right)^{2}\right] .
$$

By combining two formulas, the solution $\alpha=0.5$ is obtained without losing generality.

$$
W=0.5 W_{i}^{a}+0.5 W_{i}^{e} .
$$

\section{Results and Analysis}

4.1. Identification of Critical Sustainability Items. From the perspective of the TBL, the framework of sustainable development assessment criterion system can be divided into three dimensions of environment, economy, and society [98]. Therefore, this study starts from the three dimensions of the TBL to determine the critical sustainability items of prefabricated buildings. This study first uses the literature analysis method to conduct a retrospective analysis of relevant literature in recent years [24, 66, 99-103]. By referring to relevant literature and combining the characteristics of prefabricated buildings in China, some preliminary characterization items are extracted and summarized. One of the targets of sustainability evaluation research is to improve the reference value for formulating or implementing policies. Therefore, involving knowledgeable and experienced professionals for the selection of criteria is important. Thus, we conducted a survey on the site of the Youth Palace Project in Nansha District, Guangzhou, and invited five experts with rich experience in the construction of prefabricated buildings to conduct interviews on the selection of characterization items and increased or decreased the items depending on the opinions of the experts. Thereafter, the research invited 30 experts in China's construction industry, especially those with prefabricated construction experience, to score on the 5-point Likert scale through online e-mail and offline visit. The vast majority of experts in this survey have extensive professional experience and account for $46.67 \%$ of construction units, $20 \%$ of owner units, $24.44 \%$ of survey and design units, and $8.89 \%$ of other units. In general, the mean score of Likert scale with a scale of 1-5 indicates disagreement within the range of 1-2.4, indicates neutrality within the range of 2.5-3.4, and agrees within the range of 3.5-5. To ensure scientific and reasonable selection of items, this study eliminated the two items of "market awareness" and "community environmental satisfaction" with a weighted average score of less than 3.5 in the preliminary selected items. After a series of treatments, the critical sustainability items determined in this study are shown in Table 1, which lists the categories of each item and description of the meaning of the items. A total of 13 critical sustainability characterization items, including 5 items for economic sustainability and social sustainability and 3 items for ecological sustainability, were considered.

\subsection{IPA Implementation Process}

4.2.1. Determination of Item Importance Based on ANPEntropy Weight Method. In this study, we used the combined item weight values of ANP and entropy weight method to measure the importance of the items required in the IPA method. According to the critical sustainability items determined in Section 4.1, this study considered the sustainability of prefabricated buildings as the overall goal of the model, the three sustainability levels of economy, society, and environment as the criterion level, and the impact items of each criterion layer as the elements. In the network layer, the impact item in each criterion layer was used as an element group. After the correlation among the elements was analyzed, the ANP model diagram constructed is shown in Figure 3. After the ANP model is established, a pairwise 
TABLE 1: Critical sustainability items for prefabricated buildings.

\begin{tabular}{|c|c|c|}
\hline \multicolumn{3}{|c|}{ Prefabricated building sustainability (A) } \\
\hline Dimension & Item & Description \\
\hline \multirow{5}{*}{ Economic sustainability (B1) } & Construction cost $(\mathrm{C} 11)$ & Total expenditure for the project construction process. \\
\hline & $\begin{array}{l}\text { Operation and maintenance cost } \\
\qquad(\mathrm{C} 12)\end{array}$ & The cost needed for the operation and maintenance of the building. \\
\hline & $\begin{array}{l}\text { Construction technical difficulty } \\
\qquad(\mathrm{C} 13)\end{array}$ & Technical problems in the application of fabricated buildings. \\
\hline & Policy support (C14) & $\begin{array}{c}\text { Policy measures taken by the government to promote prefabricated } \\
\text { buildings. }\end{array}$ \\
\hline & Investment risk (C15) & Risk of investing in prefabricated buildings. \\
\hline \multirow{5}{*}{ Social sustainability (B2) } & Product quality (C21) & $\begin{array}{l}\text { Refers to building stability, user experience, reliability, and } \\
\text { aesthetics. }\end{array}$ \\
\hline & Productivity (C22) & Ratio of actual output to maximum output under fixed input. \\
\hline & Quality requirement of workers & \\
\hline & $(\mathrm{C} 24)$ & The professional skills required by construction workers. \\
\hline & $\begin{array}{l}\text { Industrial linkage development } \\
\text { (C25) }\end{array}$ & Other industry development driven by prefabricated buildings. \\
\hline \multirow{3}{*}{$\begin{array}{l}\text { Environmental sustainability } \\
\text { (B3) }\end{array}$} & Resource consumption (C31) & \multirow{3}{*}{$\begin{array}{l}\text { Resource-saving benefits from prefabricated buildings. } \\
\text { Pollutions reduced by prefabricated buildings. } \\
\text { Civilized construction method compared with traditional } \\
\text { construction. }\end{array}$} \\
\hline & Environmental protection $(\mathrm{C} 32)$ & \\
\hline & Construction civilization (C33) & \\
\hline
\end{tabular}

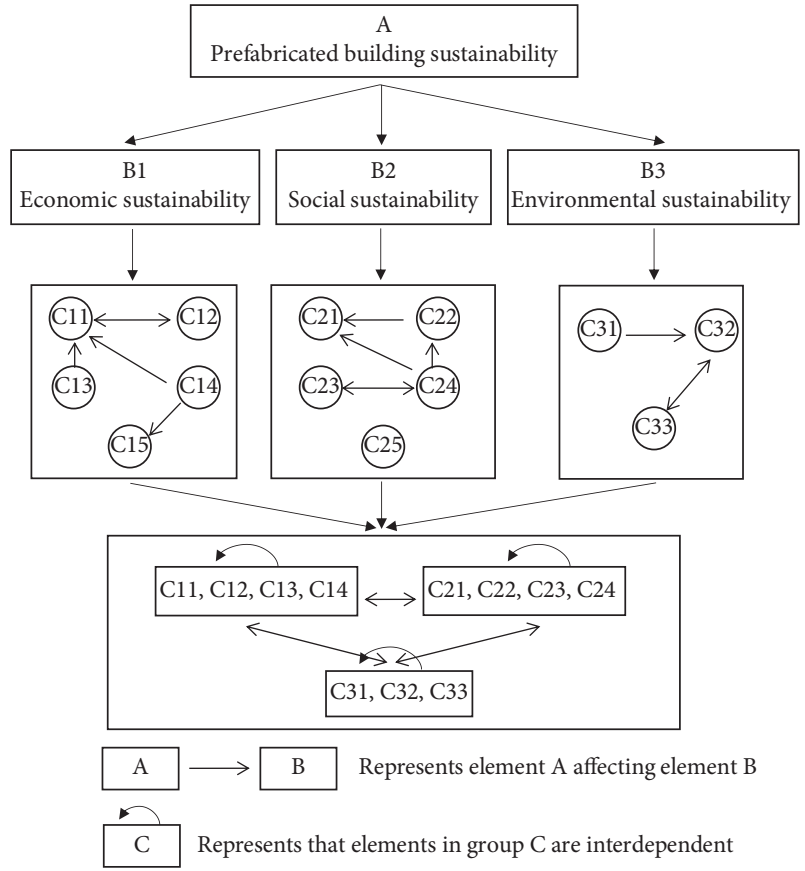

Figure 3: ANP model diagram.

judgment matrix needs to be established based on the correlation between the elements. Then, the obtained comparison data are filled into each judgment matrix to obtain an unweighted supermatrix. The ANP model is a mesh model, and its manual calculation is very complicated and needs to be implemented by computer software. Therefore, this study used the Super Decision software to calculate the weighted supermatrix and extreme supermatrix to obtain the subjective weights of each element.
ANP theory was used in this study to develop a questionnaire that meets the needs of the research. The design of the questionnaire was based on the correlation among the items. The importance of each item was compared using a 9level scale method. Questionnaires were selectively sent out to knowledgeable and experienced experts through field surveys of construction projects in Guangzhou (including the Guangzhou International Campus project of South China University of technology, which has the largest prefabricated building area in Guangzhou and meets the A-level evaluation standard) and online mail scholars and technicians to obtain research survey data. Respondents were employees from government, owner, construction, design, consulting, component production, and others, covering engineers, project managers, technicians, and other major workers in the field of engineering. More than $67 \%$ of the respondents have been in the construction engineering field for 6 years or more. Therefore, the objects of this survey have been in the engineering field for a long time, are familiar with the actual engineering construction, and have rich work experience. However, prefabricated buildings are still in the early stages of development in Guangzhou during the investigation process. Although the relevant personnel have been working in the traditional construction industry for many years, the time to participate in the construction of Guangzhou prefabricated building project is only in recent years. A total of 88 questionnaires were collected in this part of the study, and 70 valid questionnaires were obtained through screening. After the collected data were analyzed, the subjective weight of each evaluation item $W_{i}^{a}=[0.2375$ $\begin{array}{lllllllll}0.1491 & 0.0055 & 0.0281 & 0.0055 & 0.0599 & 0.0034 & 0.0513 & 0.0316\end{array}$ $\begin{array}{llllll}0.0071 & 0.0376 & 0.2027 & 0.1806\end{array}$.

In the application of the entropy weight method to obtain the objective weight of each evaluation item, the 
principle of the entropy weight method was used to develop a questionnaire. Similarly, 45 valid questionnaires were obtained in the form of field survey of Guangzhou prefabricated building project and online mail. The interviewees are some experts and scholars who fill in the ANP method questionnaire. Although the data collection method of the questionnaire is subjective, the influence of individual subjectivity can be greatly reduced by using the entropy method and increase the objectivity and rationality of the weighting results. In the questionnaire, the importance of each item was divided into five levels using Likert scales, that is, least important (1 point), less important ( 2 points), generally important ( 3 points), more important (4 points), and very important ( 5 points). Respondents judged and scored each item depending on their own experience. After the data were normalized, the entropy value of each item $e_{i}=[0.7205$ $\begin{array}{llllllll}0.7578 & 0.7068 & 0.7356 & 0.8327 & 0.7505 & 0.7417 & 0.7822 & 0.8126\end{array}$ $0.81700 .78410 .73350 .7955]$ and the objective entropy weight $W_{i}^{e}=\left[\begin{array}{llllllll}0.0923 & 0.0799 & 0.0968 & 0.0873 & 0.0552 & 0.0823 & 0.0853\end{array}\right.$

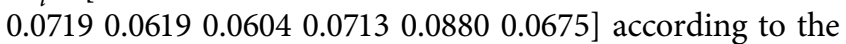
principle of calculating the entropy weight method.

According to formula (4), the subjective weights of ANP and objective weights of entropy weights were comprehensively calculated. The final summary table of weights of evaluation item is shown in Table 2.

4.2.2. IPA Results. In terms of performance data acquisition, this study targeted personnel in the field who are familiar with prefabricated buildings in Guangzhou. We sent emails to invite the respondents in the abovementioned survey to conduct a questionnaire survey and asked them to provide some other respondents who belong to the research objectives. According to the clues formed, we used the snowball method to visit the new respondents. The questionnaire has two parts: one is the background information of the interviewees, and the other involves the subjective feelings of the respondents on the sustainable performance of prefabricated buildings in Guangzhou, which were measured by a 5-level Likert scale. The scores range from 1 to 5, with higher scores indicating that the respondent's evaluation of the sustainability performance of prefabricated buildings is better. A total of 250 questionnaires were distributed in the study, and 224 valid questionnaires were recovered (validation rate of questionnaires $=89.6 \%$ ). When using Cronbach's $\alpha$ as the criterion for assessing the reliability of the questionnaire, $\alpha<0.30$ is unreliable, $0.30<\alpha<0.40$ indicates low reliability and is only acceptable in preliminary studies, $0.40<\alpha<0.50$ means slightly reliable, $0.50<\alpha<0.70$ means reliable (the most common reliable range), $0.70<\alpha<0.90$ is very reliable (the second most common range of reliability), and $0.90<\alpha$ is completely reliable [104]. In this study, Cronbach's $\alpha$ values of the three dimensions of economic sustainability, social sustainability, and environmental sustainability are $0.779,0.761$, and 0.691 , respectively. The overall Cronbach's $\alpha$ value is 0.785 , which belongs to the range of $0.70<\alpha<0.90$. Therefore, the content of the questionnaire shows high reliability and internal consistency. The results are shown in Table 3.
The background information of the interviewees collected from the questionnaire includes gender, age, education level, jobs, construction engineering field employment duration, and prefabricated building participation duration, in which the working years were calculated by rounding (Table 4). Among the 224 respondents, males account for $62.95 \%$ of the sample, which accords with the characteristics of the gender proportion in the construction engineering field. Most of the respondents are between the ages of 26 and 45 , and the number of undergraduates and above is relatively high. From the perspective of the jobs, the respondents come from different employments, and the distribution ratio is relatively balanced and ranges from $4.02 \%$ to $16.96 \%$. In terms of working duration in the construction engineering field, 6-10 years has the most frequency and accounts for $40.18 \%$ of the sample, and respondents with 11 years or more of working experience account for $38.84 \%$. Therefore, most of the respondents have a long working period in the engineering field and have rich work experience. For the construction time of prefabricated buildings, the proportion of respondents from 1 to 5 years reaches $54.46 \%$, and the total proportion of respondents from 6 years and above reaches $25.01 \%$. Those less than 1 year also occupy $20.54 \%$ of the sample. The reason is that prefabricated buildings have only begun to develop in Guangzhou and even throughout China in recent years. This result also shows that the questionnaire collected in this study can effectively reflect the current situation of the sustainable development of the prefabricated buildings in Guangzhou, which confirms the reliability of the research results to a certain extent.

Table 5 shows the results of the IPA using (1) and the Tarrant-Smith framework method (using a 95\% CI to set SE for the average performance value of each item), combined with the item comprehensive weights shown in Table 2, and the performance questionnaire survey. Table 5 presents the values of the importance of each item (the comprehensive weight of the item), the average performance of the item, SE, CI, and the TSF results. In the TSF column, “-” represents that no corresponding value exists for the median in the CI of the item; that is, no problem related to the two quadrants exists; " $x$ " represents that a corresponding value exists for the median in the CI of the item, which crosses two quadrants. The results in Table 5 indicate that the overall median values of performance and importance locate on the item C14 "policy support," which are 3.3438 and 0.0577 , respectively. Therefore, the coordinate origin of the twodimensional graph of IPA should be determined as the coordinate corresponding to the item $(3.3438,0.0577)$.

The two-dimensional IPA established by ordinal correspondence of values representing item performance and importance is shown in Figure 4. The following is a brief analysis of each quadrant according to IPA results.

Quadrant I (Keep Up the Good Work): The importance and performance of the items C32 (environmental protection), C33 (construction civilization), C12 (operation and maintenance cost), and C23 (health and safety of workers) in this quadrant are relatively high. The subsequent development of the four items should 
TABle 2: Summary table of evaluation item weights.

\begin{tabular}{lccc}
\hline Item & ANP weight & Entropy weight & Combination weight \\
\hline C11 & 0.2375 & 0.0923 & 0.1649 \\
C12 & 0.1491 & 0.0799 & 0.1145 \\
C13 & 0.0055 & 0.0968 & 0.0511 \\
C14 & 0.0281 & 0.0873 & 0.0577 \\
C15 & 0.0055 & 0.0552 & 0.0304 \\
C21 & 0.0599 & 0.0823 & 0.0711 \\
C22 & 0.0034 & 0.0853 & 0.0444 \\
C23 & 0.0513 & 0.0719 & 0.0616 \\
C24 & 0.0316 & 0.0619 & 0.0467 \\
C25 & 0.0071 & 0.0604 & 0.0338 \\
C31 & 0.0376 & 0.0713 & 0.0544 \\
C32 & 0.2027 & 0.0880 & 0.1453 \\
C33 & 0.1806 & 0.0675 & 0.1241 \\
\hline
\end{tabular}

TABLE 3: Reliability analysis.

\begin{tabular}{lcc}
\hline Dimension & $\begin{array}{c}\text { Number of } \\
\text { items }\end{array}$ & $\begin{array}{c}\text { Cronbach's } \\
\alpha \text { values }\end{array}$ \\
\hline $\begin{array}{l}\text { Economic sustainability } \\
\text { Social sustainability }\end{array}$ & 5 & 0.779 \\
Environmental & 5 & 0.761 \\
sustainability & 3 & 0.691 \\
Total & 13 & 0.785 \\
\hline
\end{tabular}

be based on the original basis to continue to maintain or promote innovation for the sustainable development of prefabricated buildings in Guangzhou.

Quadrant II (Concentrate Here): The items in the quadrant are $\mathrm{C} 11$ (construction cost) and C21 (product quality). The two items have relatively low performance but high importance. For the "construction cost" item, the weight value is the largest among all items. Therefore, improving the performance of the item is particularly urgent, and taking the improvement action for this item will have the greatest promotion effect. According to the Tarrant-Smith framework, the CI of the "product quality" item falls in the first quadrant, and we cannot determine exactly whether the performance of the item is good. However, if viewed conservatively, certain measures also need to be taken to promote the improvement of the quality of construction products for the sustainable development of prefabricated buildings.

Quadrant III (Low Priority): The items included in this quadrant are $\mathrm{C} 13$ (construction technical difficulty), C15 (investment risk), C24 (quality requirement of workers), and C25 (industrial linkage development). These items are currently relatively low in performance and importance. Therefore, the attributes of the four items are not the areas that should be focused on to promote the sustainable development of prefabricated buildings in Guangzhou nor the priority of implementing improvement measures.

Quadrant IV (Possible Overkill): The items in this quadrant are C22 (productivity) and C31 (resource consumption). The performance value is high and the development is good at present, but the importance is low. According to the Tarrant-Smith framework, the CI of the item C22 in this quadrant locates in quadrant III. Similarly, we cannot confidently determine the performance level of this item. However, according to the IPA results, if too much attention and investment are made on the item C31, then excessive waste may be generated in the process of promoting the sustainable development of prefabricated buildings in Guangzhou.

Notably, the item C14 (policy support) at the origin of the coordinates cannot be classified into any quadrant nor can it be completely separated into four quadrants. The analysis results in the IPA chart indicate that the importance and performance level of the item are in a medium state, and whether the item needs to take action for improvement is difficult to determine. However, the construction of prefabricated buildings in various regions and cities, including Guangzhou, has set off a wave since the country introduced a series of policies. Local governments have taken measures from policy, economy, and industrial technology aspects to increase policy support, research and development investment, and production university research cooperation for promoting the healthy and rapid development of prefabricated buildings [105].

\section{Discussion}

Prefabricated buildings are considered by many countries as important solutions for environmental construction and industry [43]. The data of "Forecast 2019: Panorama Map of China's Prefabricated Building Industry" in 2018 indicated that the proportion of prefabricated building areas in China's new construction area is much lower than in the United States, Japan, France, Sweden, and other developed countries. The previous IPA results show the importance and performance of the sustainability of prefabricated buildings in Guangzhou and indicate that the sustainable development of prefabricated buildings in Guangzhou is not very good. Only some prefabricated building model cities, such as Shenyang, Beijing, Shanghai, and Shenzhen, have a certain scale of industrial chain and base in terms of prefabricated building applications in China. Most domestic cities, including Guangzhou, have a weaker development trend for prefabricated buildings than a small number of model cities. The research on the sustainable performance of prefabricated buildings conducted in this study with Guangzhou as a representative also actually represents the sustainable performance of prefabricated buildings in most cities and regions in China to a certain extent. Therefore, the research results are not limited to the prefabricated buildings in Guangzhou but also have certain reference significance to other cities and regions in China.

The previous IPA results show that the items C11 (construction cost) and C21 (product quality) are in the second quadrant, which is of high importance but low performance. Since the CI of C21 mostly locates in quadrant II, for the sake of conservativeness, this item should be placed in this quadrant for analysis. By virtue of the "three- 
TABLE 4: Background information of respondents.

\begin{tabular}{|c|c|c|}
\hline \multirow{2}{*}{ Item } & \multicolumn{2}{|c|}{ Total sample $(n=224)$} \\
\hline & Number & Percentage (\%) \\
\hline \multicolumn{3}{|l|}{ Sex } \\
\hline Male & 141 & 62.95 \\
\hline Female & 83 & 37.05 \\
\hline \multicolumn{3}{|l|}{ Age } \\
\hline 25 and lower & 2 & 0.89 \\
\hline $26-35$ & 92 & 41.07 \\
\hline $36-45$ & 45 & 20.09 \\
\hline $46-55$ & 39 & 17.41 \\
\hline 56 and higher & 46 & 20.54 \\
\hline \multicolumn{3}{|l|}{ Educational level } \\
\hline High school and below & 41 & 18.30 \\
\hline Junior college & 44 & 19.64 \\
\hline Undergraduate & 64 & 28.57 \\
\hline Master & 47 & 20.98 \\
\hline Doctor & 28 & 12.50 \\
\hline \multicolumn{3}{|l|}{ Work unit } \\
\hline Government & 16 & 7.14 \\
\hline Owner & 29 & 12.95 \\
\hline Construction & 34 & 15.18 \\
\hline Survey and design & 38 & 16.96 \\
\hline Supervision & 12 & 5.36 \\
\hline Consulting & 34 & 15.18 \\
\hline Colleges and universities & 9 & 4.02 \\
\hline Prefabricated factory & 17 & 7.59 \\
\hline Others & 35 & 15.63 \\
\hline \multicolumn{3}{|c|}{ Working time in the field of construction engineering } \\
\hline 5 and lower & 47 & 20.98 \\
\hline $6-10$ & 90 & 40.18 \\
\hline $11-15$ & 20 & 8.93 \\
\hline $16-20$ & 11 & 4.91 \\
\hline $21-25$ & 19 & 8.48 \\
\hline 26 and higher & 37 & 16.52 \\
\hline \multicolumn{3}{|c|}{ Prefabricated building participation time } \\
\hline 0 & 46 & 20.54 \\
\hline $1-2$ & 39 & 17.41 \\
\hline $3-5$ & 83 & 37.05 \\
\hline $6-10$ & 33 & 14.73 \\
\hline $11-15$ & 6 & 2.68 \\
\hline $16-20$ & 7 & 3.13 \\
\hline $21-25$ & 4 & 1.79 \\
\hline 26 and higher & 6 & 2.68 \\
\hline
\end{tabular}

factor theory" proposed by Kano et al. [106], C11 and C21 belong to the "fundamental factors" of the three factors. The so-called "basic factors"; that is, if these factors are not satisfied, they will bring dissatisfactory effects; however, if they are satisfied or better than expected, they are not necessarily satisfactory. The negative performance of these factors will have a greater impact on the development level of overall performance than the positive performance. "Basic factors" are prerequisites for the product [107]. Therefore, taking management actions to improve the performance of the items "construction cost" and "product quality" is particularly urgent to improve the sustainability level of prefabricated buildings in Guangzhou. The item C14 (policy support) at the origin of IPA coordinates also needs special attention. In fact, the policy requiring the implementation of prefabricated buildings has greatly promoted the development of China's prefabricated industry [108]. Although the Chinese government has proposed a series of policies for the development of prefabrication in recent years [109], the implementation of prefabrication in China still lags behind those in other developed countries [110]. Previous studies have shown concerns about potentially high capital costs or even high total costs in prefabricated construction projects [111]. Many studies have shown that the unit cost of prefabricated buildings is estimated to be $2 \%-17 \%$ higher than that of traditional buildings $[20,111]$. Prefabricated buildings are still in the initial stage of development in China [112]. Thus, cost issues play an important role in the decision-making process when choosing innovative building methods. This is also the main factor that hinders the 
TABLE 5: Importance-performance analysis results.

\begin{tabular}{|c|c|c|c|c|c|}
\hline \multirow{2}{*}{ Item } & \multicolumn{4}{|c|}{ Performance } & \multirow{2}{*}{ Importance } \\
\hline & Average value & SE & $\mathrm{CI}$ & TSF & \\
\hline $\mathrm{C} 11$ & 2.9777 & 0.0768 & $(2.9009,3.0545)$ & - & 0.1649 \\
\hline $\mathrm{C} 12$ & 3.5714 & 0.0768 & $(3.4946,3.6482)$ & - & 0.1145 \\
\hline $\mathrm{C} 13$ & 3.0982 & 0.0777 & $(3.0205,3.1759)$ & - & 0.0511 \\
\hline $\mathrm{C} 14$ & 3.3438 & 0.0811 & $(3.2627,3.4248)$ & $\times$ & 0.0577 \\
\hline C15 & 3.1920 & 0.0804 & $(3.1116,3.2724)$ & - & 0.0304 \\
\hline $\mathrm{C} 21$ & 3.2902 & 0.0830 & $(3.2072,3.3732)$ & $x$ & 0.0711 \\
\hline $\mathrm{C} 22$ & 3.4063 & 0.0902 & $(3.3161,3.4964)$ & - & 0.0444 \\
\hline $\mathrm{C} 23$ & 3.4911 & 0.0847 & $(3.4064,3.5757)$ & - & 0.0616 \\
\hline $\mathrm{C} 24$ & 3.1518 & 0.0882 & $(3.0636,3.2400)$ & - & 0.0467 \\
\hline $\mathrm{C} 25$ & 3.2455 & 0.0892 & $(3.1563,3.3347)$ & - & 0.0338 \\
\hline $\mathrm{C} 31$ & 3.7455 & 0.0763 & $(3.6693,3.8218)$ & - & 0.0544 \\
\hline $\mathrm{C} 32$ & 4.0045 & 0.0683 & $(3.9362,4.0728)$ & - & 0.1453 \\
\hline $\mathrm{C} 33$ & 3.7098 & 0.0754 & $(3.6344,3.7852)$ & - & 0.1241 \\
\hline
\end{tabular}

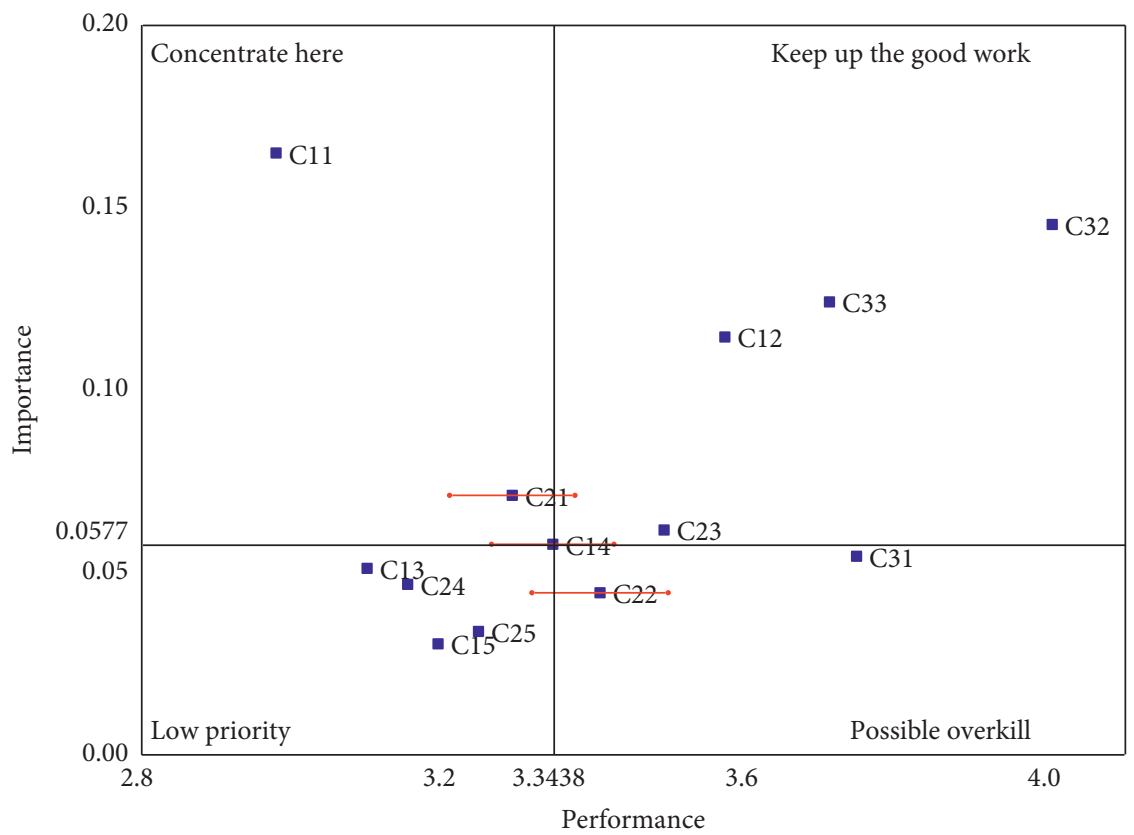

FIgURE 4: IPA results.

construction industry from advancing prefabricated buildings as highlighted in the literature and pilot project research $[16,113]$. Many consumers think that prefabricated buildings are inferior low-end products; they are also skeptical of prefabricated buildings due to a series of quality problems, such as poor seismic performance and weak thermal insulation performance in the process of developing prefabricated buildings in China $[114,115]$.

The use of prefabricated construction will likely conflict with the project's economic interests, which inevitably reduces the developer's willingness. Because in the construction industry investment market, it is profit-oriented. Projects without profit or even causing losses will affect the investment enthusiasm. Some measures should be taken to solve this problem and promote the sustainable economic development of prefabricated buildings. In recent years, prefabricated buildings have shown a continuous development trend driven by policies [43]. Mao et al. [116] emphasized that the regulations and policies issued by the government have a crucial impact on the widespread application of prefabricated buildings. The government should adopt a positive attitude to formulate strategies and policies for promoting the implementation of prefabricated buildings. Jiang et al. [117] also put forward this opinion and gave a detailed policy system and feasible guidelines to solve the obstacles in the current implementation of prefabricated buildings. However, the construction cost of prefabricated buildings has remained high because of the significant increase in the production and installation costs of prefabricated components [101]. Therefore, the development of domestic prefabricated buildings in the current initial stage should be promoted with policy incentives as the guide. For developers, sufficient concessions can be given in terms of land use and taxation to reduce development costs and encourage developers to choose prefabricated construction methods. For manufacturers of prefabricated components, 
certain subsidy policies can be adopted to encourage largescale production by enterprises. The resulting economies of scale can reduce overall construction costs and improve cost efficiency. For consumers, appropriate economic subsidies can be adopted to increase their willingness to purchase prefabricated houses. Moreover, product quality is also one of the important affecting factors of the development of prefabricated buildings. This factor includes various aspects, the quality of the house, the performance, and the diverse design requirements. Tool-based assistance and automatic control in the manufacturing process should be used to further improve the accuracy of components, reduce the frequency of replacement during the building operation phase, and develop environmentally friendly multiperformance building materials. It will increase the economic benefits of consumer use and facilitate public acceptance by this way. Only when the public accepts the quality of the building, can the developer's willingness and motivation to invest in prefabricated buildings be strengthened to effectively achieve the sustainable and stable development of prefabricated buildings. It is worth mentioning that governments in different regions should adapt to local conditions and improve local policy incentives. Guangzhou, which is one of the few first-tier cities and international business centers in China, has strong talents and scientific and technological resources. The city should take advantage of its strong economy and resource advantages to promote the development of its fabricated buildings.

\section{Conclusion}

This study investigates the importance and performance level of the sustainability of prefabricated buildings by taking Guangzhou as a study case. According to the sustainability dimension contained in TBL, this study identifies critical sustainability characterization items for prefabricated buildings. On this basis, this study attempts to amend the IPA method and introduce it into the research of the construction industry by surveying the employees of the relevant fields in prefabricated buildings. IPA provides a simplified method to analyze the importance and performance level of the research object, which helps identify the most critical aspects that require special attention. The ANPentropy weight method can determine the weight of each interacting item under different circumstances of knowledge and experience for obtaining more scientific and comprehensive weight results. The results show that "construction cost" and "product quality" are considered high-importance but low-performance items, which need to be focused on and take measures to promote improvement. The "policy support" item at the intersection of IPA coordinates is also an aspect worthy of attention and discussion. Effective policy incentives will greatly promote the development of domestic prefabricated buildings in China, which is still in the early development stage.

Although this study takes the importance and performance evaluation of the sustainability of prefabricated buildings in Guangzhou as an example, the results have certain reference significance and enlightenment for the sustainability evaluation research of prefabricated buildings in other cities in China and other countries as well. The research ideas and results of this study can provide a new reference for the sustainability research methods of prefabricated buildings. The main contributions of the research are as follows: (1) from the perspective of research methods, this study has made various amendments to the IPA method. In particular, the combination of the ANP method that considers the interaction among criteria and the objective entropy weight method is used as a measure of the importance of items. It overcomes the shortcomings of existing research and is applied to the research field of prefabricated buildings. In the current research related to the construction field, IPA has not been widely and effectively applied. Although some research results on the sustainability evaluation of prefabricated buildings are available, measurement of the simultaneous analysis of the importance and performance level of critical items is lacking. This study further shows that the modified IPA method can evaluate and measure the importance and performance level of items and provide management recommendations for each item in the construction field. This study shows an example for future IPA research in the field of construction and provides a feasible method and idea, which helps enrich the current knowledge system. (2) In terms of evaluation results, this study comprehensively considered the sustainability of the three dimensions of TBL (economic, social, and ecological), making up for the deficiencies that most current studies only analyze the sustainability of single or limited dimensions. According to the results of a survey to investigate the importance and performance level of the sustainability of prefabricated buildings in Guangzhou, the critical items that are in urgent need of improvement and the priorities for the implementation of management measures are identified. And the corresponding development countermeasures are proposed on the basis of the evaluation results. This study provides a new research perspective for the sustainable development strategy of future prefabricated buildings. Through this perspective, a theoretical basis can be provided for promoting the sustainable construction and operation management of prefabricated buildings. The related theoretical results and conclusions studied in this work can also provide certain references for decision-makers and construction companies.

The IPA results of the sustainable development of prefabricated buildings in this article can help practitioners and decision-makers in the construction industry understand the sustainability and performance level of prefabricated buildings in each sustainability dimension and under the overall TBL to select sustainable best plan. However, sustainable development is a dynamic process and thus changes over time. It also depends on many parameters, and the regional differences exist among prefabricated construction projects in different places. Prefabricated building is an effective way to promote the industrialization of the construction industry and is also popular in recent years. Therefore, further exploring of sustainability evaluation and research methods is still necessary. In the future 
research, more consideration may need to be given to the completeness of sustainability coverage and the balance between applicability and dynamic effectiveness to apply assessment methods and results in more real-time and effective ways.

\section{Data Availability}

All data generated or used during the study are available from the corresponding author by request.

\section{Disclosure}

This paper is based on a conference paper presented at the Construction Research Congress 2020, Tempe, Arizona, United States.

\section{Conflicts of Interest}

The authors declare no conflicts of interest.

\section{Acknowledgments}

The authors gratefully acknowledge the funding and support provided by the National Natural Science Foundation of China (Grant no. 71871096).

\section{References}

[1] F. Al-Nassar, R. Ruparathna, G. Chhipi-Shrestha, H. Haider, K. Hewage, and R. Sadiq, "Sustainability assessment framework for low rise commercial buildings: life cycle impact index-based approach," Clean Technologies and Environmental Policy, vol. 18, no. 8, pp. 2579-2590, 2016.

[2] H. Kang, Y. Lee, and S. Kim, "Sustainable building assessment tool for project decision makers and its development process," Environmental Impact Assessment Review, vol. 58, pp. 34-47, 2016.

[3] Z. Xu, X. Wang, and W. Zhou, "Integration study on the evaluation method of green construction based on ontology and BIM," Advances in Civil Engineering, vol. 2019, Article ID 1609523, 18 pages, 2019.

[4] Yuan, IPCC Fourth Assessment Report: Climate Change 2007 (AR4), Working Group I: 5e Physical Science Basis, IPCC Intergovernmental Panel on Climate Change, Geneva, Switzerland, 2007.

[5] EU, "Energy performance of buildings," EU, Brussels, Belgium, 2014, https://ec.europa.eu/energy/en/topics/energyefficiency/energy-performance-of-buildings.

[6] Z. Chen, C. An, H. Fang et al., "Assessment of regional greenhouse gas emission from beef cattle production: a case study of Saskatchewan in Canada," Journal of Environmental Management, vol. 264, 2020.

[7] A. Elmualim and D. Alp, "Perception and challenges for sustainable construction in developing countries: north Cyprus case," Journal of Civil Engineering and Architecture, vol. 10, no. 4, pp. 492-500, 2016.

[8] A. Bakchan and K. M. Faust, "Construction waste generation estimates of institutional building projects: leveraging waste hauling tickets," Waste Management, vol. 87, pp. 301-312, 2019.

[9] U. A. Umar, N. Shafiq, A. Malakahmad, M. F. Nuruddin, and M. F. Khamidi, "A review on adoption of novel techniques in construction waste management and policy," Journal of Material Cycles and Waste Management, vol. 19, no. 4, pp. 1361-1373, 2017.

[10] A. Barbudo, J. Ayuso, A. Lozano, M. Cabrera, and A. LópezUceda, "Recommendations for the management of construction and demolition waste in treatment plants," Environmental Science and Pollution Research, vol. 27, no. 1, pp. 125-132, 2020.

[11] W. Zhang, M. W. Lee, L. Jaillon, and C.-S. Poon, "The hindrance to using prefabrication in Hong Kong's building industry," Journal of Cleaner Production, vol. 204, pp. 70-81, 2018.

[12] V. W. Y. Tam and J. J. L. Hao, "Prefabrication as a mean of minimizing construction waste on site," International Journal of Construction Management, vol. 14, no. 2, pp. 113-121, 2014.

[13] Z. Li, G. Q. Shen, and X. Xue, "Critical review of the research on the management of prefabricated construction," Habitat International, vol. 43, pp. 240-249, 2014.

[14] W. T. Chan and H. Hu, "Constraint programming approach to precast production Scheduling," Journal of Construction Engineering and Management, vol. 128, no. 6, pp. 513-521, 2002.

[15] N. Blismas, C. Pasquire, and A. Gibb, "Benefit evaluation for off-site production in construction," Construction Management and Economics, vol. 24, no. 2, pp. 121-130, 2006.

[16] V. W. Y. Tam, I. W. H. Fung, M. C. P. Sing, and S. O. Ogunlana, "Best practice of prefabrication implementation in the Hong Kong public and private sectors," Journal of Cleaner Production, vol. 109, pp. 216-231, 2015.

[17] P. S. Wong, C. Zwar, and E. Gharaie, "Examining the drivers and states of organizational change for greater use of prefabrication in construction projects," Journal of Construction Engineering \& Management, vol. 143, Article ID 04017020, 2017.

[18] J. Du, H. Jing, D. Castro-Lacouture, and V. Sugumaran, "Multi-agent simulation for managing design changes in prefabricated construction projects," Engineering, Construction and Architectural Management, vol. 27, no. 1, pp. 270-295, 2019.

[19] Y. Ji, S. Chang, Y. Qi, Y. Li, H. X. Li, and K. Qi, “A BIM-based study on the comprehensive benefit analysis for prefabricated building projects in China," Advances in Civil Engineering, vol. 2019, Article ID 3720191, 13 pages, 2019.

[20] W. Lu and H. Yuan, "Investigating waste reduction potential in the upstream processes of offshore prefabrication construction," Renewable and Sustainable Energy Reviews, vol. 28, pp. 804-811, 2013.

[21] G. Tumminia, F. Guarino, S. Longo, M. Ferraro, M. Cellura, and V. Antonucci, "Life cycle energy performances and environmental impacts of a prefabricated building module," Renewable and Sustainable Energy Reviews, vol. 92, pp. 272-283, 2018.

[22] W. Nadim and J. S. Goulding, "Offsite production in the UK: the way forward? A UK construction industry perspective," Construction Innovation, vol. 10, no. 2, pp. 181-202, 2010.

[23] Y. Chang, X. D. Li, E. Masanet, L. X. Zhang, Z. Y. Huang, and R. Ries, "Resources, conservation \& recycling," vol. 139, pp. 259-261, Elsevier, Amsterdam, Netherlands, 2018.

[24] K. Mohammad and H. Kasun, "Development of performance criteria for sustainability evaluation of modular versus conventional construction methods," Journal of Cleaner Production, vol. 142, pp. 3592-3606, 2017.

[25] E. A. M. Bevan and P. Yung, "Implementation of corporate social responsibility in Australian construction SMEs," 
Engineering, Construction and Architectural Management, vol. 22, no. 3, pp. 295-311, 2015.

[26] L. Zhang and J. Zhou, "The effect of carbon reduction regulations on contractors' awareness and behaviors in China's building sector," Journal of Cleaner Production, vol. 113, pp. 93-101, 2015.

[27] P. Yi, W. Li, and D. Zhang, "Assessment of city sustainability using MCDM with interdependent criteria weight," Sustainability, vol. 11, no. 6, p. 1632, 2019.

[28] S. Wagenhals, W. Garner, L. Duckers, and K. Kuhn, "Sustainability index with integrated indicator dependencies," Business, Management and Education, vol. 12, no. 1, pp. 15-29, 2014.

[29] P. C. Y. Liu, H.-W. Lo, and J. J. H. Liou, "A combination of DEMATEL and BWM-based ANP methods for exploring the green building rating system in Taiwan," Sustainability, vol. 12, no. 8, p. 3216, 2020.

[30] J. Gao, H. Ren, and W. Cai, "Risk assessment of construction projects in China under traditional and industrial production modes," Engineering, Construction and Architectural Management, vol. 26, no. 9, pp. 2147-2168, 2019.

[31] G. Liu, R. Chen, P. Xu, Y. Fu, C. Mao, and J. Hong, "Realtime carbon emission monitoring in prefabricated construction," Automation in Construction, vol. 110, Article ID 102945, 2020.

[32] Q. Wang, Z. Guo, T. Mei, Q. Li, and P. Li, "Labor crew workspace analysis for prefabricated assemblies' installation," Engineering, Construction and Architectural Management, vol. 25, no. 3, pp. 374-411, 2018.

[33] L. Xu, F. Zha, C. Liu, and B. Kang, "Experimental investigation on carbonation behavior in lime-stabilized expansive soil," Advances in Civil Engineering, vol. 2020, Article ID 8946530, 21 pages, 2020.

[34] J. Liu, G. Q. Shen, C. Mao, Z. Li, and K. Li, "Life-cycle energy analysis of prefabricated building components: an inputoutput-based hybrid model," Journal of Cleaner Production, vol. 112, pp. 2198-2207, 2016.

[35] S. Kale and D. Arditi, "Diffusion of ISO 9000 certification in the precast concrete industry," Construction Management and Economics, vol. 24, no. 5, pp. 485-495, 2006.

[36] H. Jonsson and M. Rudberg, "Classification of production systems for industrialized building: a production strategy perspective," Construction Management and Economics, vol. 32, no. 1-2, pp. 1-17, 2014.

[37] J. H. Meiling, M. Sandberg, and H. Johnsson, "A study of a plan-do-check-act method used in less industrialized activities: two cases from industrialized housebuilding," Construction Management and Economics, vol. 32, no. 1-2, pp. 1-17, 2013.

[38] W. Pan, A. G. F. Gibb, and A. R. J. Dainty, "Leading UK housebuilders' utilization of offsite construction methods," Building Research \& Information, vol. 36, no. 1, pp. 56-67, 2008.

[39] C. Rocha, C. Formoso, and P. Tzortzopoulos, "Adopting product modularity in house building to support mass customisation," Sustainability, vol. 7, no. 5, pp. 4919-4937, 2015.

[40] W. S. Zhao, B. B. Zhang, and Y. Yang, "Empirical study of comprehensive benefits for prefabricated buildings: a case study of Hefei city," The International Journal of Electrical Engineering \& Education, 2020.

[41] S. Q. Wang, J. Tang, Y. Q. Zou, and Q. H. Zhou, "Research on production process optimization of precast concrete component factory based on value stream mapping,"
Engineering, Construction and Architectural Management, vol. 27, no. 4, 2019.

[42] Z. Xu, T. Zayed, and Y. Niu, "Comparative analysis of modular construction practices in mainland China, Hong Kong and Singapore," Journal of Cleaner Production, vol. 245, Article ID 118861, 2020.

[43] W. P. Jiang, L. R. Luo, Z. Z. Wu, J. B. Fei, M. F. Antwi-Afari, and T. Yu, "An investigation of the effectiveness of prefabrication incentive policies in China," Sustainability, vol. 11, no. 19, p. 5149, 2019.

[44] D. Yeoh and M. Fragiacomo, "The design of a semi-prefabricated LVL-concrete composite floor," Advances in Civil Engineering, vol. 2012, Article ID 626592, 19 pages, 2012.

[45] N. Boyd, M. M. A. Khalfan, and T. Maqsood, "Off-site construction of apartment buildings," Journal of Architectural Engineering, vol. 19, no. 1, pp. 51-57, 2013.

[46] V. W. Y. Tam, C. M. Tam, S. X. Zeng, and W. C. Y. Ng, "Towards adoption of prefabrication in construction," Building and Environment, vol. 42, no. 10, pp. 3642-3654, 2007.

[47] X. Cao, X. Li, Y. Zhu, and Z. Zhang, "A comparative study of environmental performance between prefabricated and traditional residential buildings in China," Journal of Cleaner Production, vol. 109, pp. 131-143, 2015.

[48] H. Wang, Y. Zhang, W. Gao, and S. Kuroki, "Life cycle environmental and cost performance of prefabricated buildings," Sustainability, vol. 12, no. 7, p. 2609, 2020.

[49] WCED, Our Common Future, Oxford University Press, Oxford, NY, USA, 1987.

[50] A. Sev, "How can the construction industry contribute to sustainable development? A conceptual framework," Sustainable Development, vol. 17, no. 3, pp. 161-173, 2009.

[51] L. Bragança, R. Mateus, and H. Koukkari, "Building sustainability assessment," Sustainability, vol. 2, no. 7, pp. 2010-2023, 2010.

[52] T. Saunders, "A discussion document comparing international environmental assessment methods for buildings," 2017, http://www.prres.net/Proceedings/..\%5CPapers\%5CReed_ International_Rating_Tools.pdf.

[53] R. Reed, A. Bilos, S. Wilkinson, and K. Schulte, "International comparison of sustainable rating tools," The Journal of Sustainable Real Estate, vol. 1, no. 1, pp. 1-22, 2009.

[54] E. Conte and V. Monno, "Beyond the buildingcentric approach: a vision for an integrated evaluation of sustainable buildings," Environmental Impact Assessment Review, vol. 34, pp. 31-40, 2012.

[55] F. Yang, Z. Li, and Y. B. Yuan, "Study on evaluation method of sustainable development of construction industry," Journal of Engineering Management, vol. 24, no. 3, pp. 258-261, 2010.

[56] H. Zabihi, F. Habib, and L. Mirsaeedie, "Definitions, concepts and new directions in industrialized building systems (IBS)," KSCE Journal of Civil Engineering, vol. 17, no. 6, pp. 1199-1205, 2013.

[57] W.-H. Tsai, S.-J. Lin, Y.-F. Lee, Y.-C. Chang, and J.-L. Hsu, "Construction method selection for green building projects to improve environmental sustainability by using an MCDM approach," Journal of Environmental Planning and Management, vol. 56, no. 10, pp. 1487-1510, 2013.

[58] T. Wongbumru and B. Dewancker, "Post-occupancy evaluation of user satisfaction: a case study of "old" and "new" public housing schemes in Bangkok," Architectural Engineering and Design Management, vol. 12, no. 2, pp. 107-124, 2016. 
[59] J. O. Atanda and A. Öztürk, "Social criteria of sustainable development in relation to green building assessment tools," Environment, Development and Sustainability, vol. 22, no. 1, pp. 1-27, 2018.

[60] G. K. C. Ding, "Developing a multicriteria approach for the measurement of sustainable performance," Building Research \& Information, vol. 33, no. 1, pp. 3-16, 2005.

[61] K. Yong-Woo and B. Jinwoo, "Assessing the environmental impacts of a lean supply system: case study of high-rise condominium construction in Korea," Journal of Architectural Engineering, vol. 16, no. 4, pp. 144-150, 2010.

[62] Y. H. Dong, L. Jaillon, P. Chu, and C. S. Poon, "Comparing carbon emissions of precast and cast-in-situ construction methods - a case study of high-rise private building," Construction and Building Materials, vol. 99, pp. 39-53, 2015.

[63] K. Mohammad and H. Kasun, "Life cycle performance of modular buildings: a critical review," Renewable and Sustainable Energy Reviews, vol. 62, pp. 1171-1183, 2016.

[64] G. Liu, T. Gu, P. Xu, J. Hong, A. Shrestha, and I. Martek, “A production line-based carbon emission assessment model for prefabricated components in China," Journal of Cleaner Production, vol. 209, no. 1, pp. 30-39, 2019.

[65] K. B. Li, B. K. Qi, and H. Wang, "Analysis of the restrictive factors of the development of prefabricated buildings based on DEMATEL," Housing Industry, no. 8, pp. 49-51, 2013.

[66] Y. Riduan and J. Yang, "Improving ecological performance of industrialized building systems in Malaysia," Construction Management and Economics, vol. 32, no. 1-2, pp. 183-195, 2014.

[67] R. D. Chang, J. Zuo, V. Soebarto, Z. Y. Zhao, G. Zillante, and X. L. Gan, "Discovering the transition pathways toward sustainability for construction enterprises: importance-performance analysis," Journal of Construction Engineering and Management, vol. 143, no. 6, Article ID 04017013, 2017.

[68] R. D. Chang, J. Zuo, Z. Y. Zhao et al., "Sustainability attitude and performance of construction enterprises: a China study," Journal of Cleaner Production, vol. 172, pp. 1440-1451, 2017.

[69] State Council of the People's Republic of China, Guidelines on the Development of Prefabricated Buildings in China, State Council of the People's Republic of China, Beijing, China, 2016.

[70] J. A. Martilla and J. C. James, "Importance-performance analysis," Journal of Marketing, vol. 41, no. 1, pp. 77-79, 1977.

[71] N. Johns, "Importance-performance analysis using the profile accumulation technique," The Service Industries Journal, vol. 21, no. 3, pp. 49-63, 2001.

[72] K. Matzler, E. Sauerwein, and K. Heischmidt, "Importanceperformance analysis revisited: the role of the factor structure of customer satisfaction," The Service Industries Journal, vol. 23, no. 2, pp. 112-129, 2003.

[73] N. M. Levenburg and S. R. Magal, "Applying importanceperformance analysis to evaluate e-business strategies among small firms," E-service Journal, vol. 3, no. 3, pp. 29-48, 2005.

[74] W. Deng, "Using a revised importance-performance analysis approach: the case of Taiwanese hot springs tourism," Tourism Management, vol. 28, no. 5, pp. 1274-1284, 2007.

[75] J. F. Cohen, E. Coleman, and M. J. Kangethe, “An importance-performance analysis of hospital information system attributes: a nurses' perspective," International Journal of Medical Informatics, vol. 86, pp. 82-90, 2016.

[76] I. K. W. Lai and M. Hitchcock, "A comparison of service quality attributes for stand-alone and resort-based luxury hotels in Macau: 3-Dimensional importance-performance analysis," Tourism Management, vol. 55, pp. 139-159, 2016.
[77] B. Phadermrod, R. M. Crowder, and G. B. Wills, "Importance-performance analysis based SWOT analysis," International Journal of Information Management, vol. 44, pp. 194-203, 2019.

[78] L. S. L. Lai and W. M. To, "Importance-performance analysis for public management decision making," Management Decision, vol. 48, no. 2, pp. 277-295, 2010.

[79] Z.-L. Wang, H.-C. Shen, and J. Zuo, "Risks in prefabricated buildings in China: importance-performance analysis approach," Sustainability, vol. 11, no. 12, p. 3450, 2019.

[80] H.-S. Lee, "Measurement of visitors' satisfaction with public zoos in Korea using importance-performance analysis," Tourism Management, vol. 47, pp. 251-260, 2015.

[81] B. B. Boley, N. G. McGehee, and A. L. Tom Hammett, "Importance-performance analysis (IPA) of sustainable tourism initiatives: the resident perspective," Tourism Management, vol. 58, pp. 66-77, 2017.

[82] J. Hua and W. Y. Chen, "Prioritizing urban rivers' ecosystem services: an importance-performance analysis," Cities, vol. 94, pp. 11-23, 2019.

[83] J. J. Kim, Y. Lee, and H. Han, "Exploring competitive hotel selection attributes among guests: an importance-performance analysis," Journal of Travel \& Tourism Marketing, vol. 36, no. 9, pp. 998-1011, 2019.

[84] E. Azzopardi and R. Nash, "A critical evaluation of importance-performance analysis," Tourism Management, vol. 35, pp. 222-233, 2013.

[85] L. Mouthino, P. Rita, and B. Curry, Expert Systems in Tourism Marketing, Routledge, London, UK, 1996.

[86] A. L. P. Freitas, "Assessing the quality of intercity road transportation of passengers: an exploratory study in Brazil," Transportation Research Part A: Policy and Practice, vol. 49, pp. 379-392, 2013.

[87] M. A. Tarrant and E. K. Smith, "The use of a modified importance-performance framework to examine visitor satisfaction with attributes of outdoor recreation settings," Managing Leisure, vol. 7, no. 2, pp. 69-82, 2002.

[88] M. Sahoo, S. Sahoo, A. Dhar, and B. Pradhan, "Effectiveness evaluation of objective and subjective weighting methods for aquifer vulnerability assessment in urban context," Journal of Hydrology, vol. 541, pp. 1303-1315, 2016.

[89] T.-C. Wang and H.-D. Lee, "Developing a fuzzy TOPSIS approach based on subjective weights and objective weights," Expert Systems With Applications, vol. 36, no. 5, pp. 89808985, 2009.

[90] H. Guo, W. Qiao, and Y. Zheng, "Effectiveness evaluation of financing platform operation of buildings energy saving transformation using ANP-fuzzy in China: an empirical study," Sustainability, vol. 12, no. 7, p. 2826, 2020.

[91] Z. Chen, H. Li, A. Ross, M. M. Khalfan, and S. C. Kong, "Knowledge-driven ANP approach to vendors evaluation for sustainable construction," Journal of Construction Engineering and Management, vol. 134, no. 12, pp. 928-941, 2008.

[92] F. Yücelgazi and İ. yitmen, "An ANP model for risk response assessment in large scale bridge projects," Civil Engineering and Environmental Systems, vol. 37, no. 1-2, pp. 1-27, 2020.

[93] P. Xu, E. H. W. Chan, H. J. Visscher, X. Zhang, and Z. Wu, "Sustainable building energy efficiency retrofit for hotel buildings using EPC mechanism in China: analytic Network Process (ANP) approach," Journal of Cleaner Production, vol. 107, pp. 378-388, 2015.

[94] Y. Ji, G. H. Huang, and W. Sun, "Risk assessment of hydropower stations through an integrated fuzzy entropy- 
weight multiple criteria decision making method: a case study of the Xiangxi river," Expert Systems with Applications, vol. 42, no. 12, pp. 5380-5389, 2015.

[95] A. Malekian and A. Azarnivand, "Application of integrated shannon's entropy and VIKOR techniques in prioritization of flood risk in the shemshak watershed, Iran," Water Resources Management, vol. 30, no. 1, pp. 409-425, 2016.

[96] Y. D. Dou and X. L. Xue, "Evaluation of industrialized construction capability of construction enterprises based on AHP-entropy method," in Proceedings of the ICCREM 2017, pp. 199-206, November 2017, Guangzhou, China.

[97] Y. Tang, Research on Performance Evaluation of Scientific Research Projects in Zhejiang Universities Based on AHPEntropy Weight Method, Zhejiang University of Technology, Hangzhou, China, 2012.

[98] G. D. Wu, K. F. Duan, J. Zuo, X. B. Zhao, and D. Z. Tang, "Integrated sustainability assessment of public rental housing community based on a hybrid method of AHPentropy weight and cloud model," Sustainability, vol. 9, no. 4, p. 603, 2017.

[99] Y. Chen, G. E. Okudan, D. R. Riley, and R. David, "Sustainable performance criteria for construction method selection in concrete buildings," Automation in Construction, vol. 19, no. 2, pp. 235-244, 2010.

[100] J. Hong, G. Q. Shen, Z. Li, B. Zhang, and W. Zhang, "Barriers to promoting prefabricated construction in China: a costbenefit analysis," Journal of Cleaner Production, vol. 172, pp. 649-660, 2018.

[101] B. K. Qi, Y. Zhu, B. Ma, and S. Liu, "Research on comprehensive benefit analysis method of prefabricated buildings," Construction Technology, vol. 45, no. 4, pp. 39-43, 2016.

[102] Z. F. Li, N. Zhang, and C. Fu, "Research on comprehensive benefit evaluation of housing industrialization based on set pair analysis theory," Journal of Engineering Management, vol. 30, no. 2, pp. 7-11, 2016.

[103] P. D. Sang and Y. J. Wang, "Restrictive factors for prefabricated house development-based on principal component analysis," Journal of Engineering Management, vol. 32, no. 6, pp. 23-28, 2018.

[104] P.-Z. Chen and W.-Y. Liu, “Assessing management performance of the national forest park using impact rangeperformance analysis and impact-asymmetry analysis," Forest Policy and Economics, vol. 104, pp. 121-138, 2019.

[105] P. D. Sang and J. X. Li, "Risk evaluation of development and construction of prefabricated building project based on structural equation," Journal of Civil Engineering and Management, vol. 34, no. 4, pp. 89-95, 2017.

[106] N. Kano, N. Seraku, F. Takahashi, and S. Tsuji, "Attractive quality and must-be quality, hinshitsu," The Journal of Japanese Society for Quality Control, vol. 14, pp. 39-48, 1984.

[107] K. Mauler and E. Sauerwein, "The factor structure of customer safisfaction: an empirical test of the importance grid and the penalty-reward- contrast analysis," International Journal of Service Industry Management, vol. 13, no. 4, pp. 314-323, 2002.

[108] X. Gan, R. Chang, and T. Wen, "Overcoming barriers to offsite construction through engaging stakeholders: a two-mode social network analysis," Journal of Cleaner Production, vol. 201, pp. 735-747, 2018.

[109] F. Yao, Y. Ji, H. X. Li et al., "Evaluation of informatization performance of construction industrialization EPC enterprises in China," Advances in Civil Engineering, vol. 2020, Article ID 1314586, 18 pages, 2020.
[110] L. Jiang, Z. Li, L. Li, and Y. Gao, "Constraints on the promotion of prefabricated construction in China," Sustainability, vol. 10, no. 7, p. 2516, 2018.

[111] L. Jaillon, C. S. Poon, and Y. H. Chiang, "Quantifying the waste reduction potential of using prefabrication in building construction in Hong Kong," Waste Management, vol. 29, no. 1, pp. 309-320, 2009.

[112] X.-L. Gan, R.-D. Chang, C. Langston, and T. Wen, "Exploring the interactions among factors impeding the diffusion of prefabricated building technologies," Engineering, Construction and Architectural Management, vol. 26, no. 3, pp. 535-553, 2019.

[113] X. Zhai, R. Reed, and A. Mills, "Factors impeding the offsite production of housing construction in China: an investigation of current practice," Construction Management and Economics, vol. 32, no. 1-2, pp. 40-52, 2014.

[114] G. C. Liu, Z. D. Wen, and J. Shen, "Influencing factors of the development of prefabricated building based on ISM," Journal of Shenyang Jianzhu University (Social Science Edition), vol. 20, no. 4, pp. 377-382, 2018.

[115] Y. F. Shi, Y. Kang, and X. F. Wang, "Research on development countermeasures of prefabricated buildings in China based on SWOT analysis," Building Economy, vol. 37, no. 11, pp. 5-9, 2016.

[116] C. Mao, Q. P. Shen, W. Pan, and K. H. Ye, "Major barriers to off-site construction:The developers' perspective in China," Journal of Management in Engineering, vol. 31, no. 3, Article ID 04014043, 2015.

[117] R. Jiang, C. Mao, L. Hou, C. Wu, and J. Tan, “A SWOT analysis for promoting off-site construction under the backdrop of China's new urbanisation," Journal of Cleaner Production, vol. 173, pp. 225-234, 2018. 